\title{
STATIC, DYNAMIC AND IMPACT STRESS ANALYSIS OF A BUS BODY
}

\section{STRUCTURE USING FINITE ELEMENT ANALYSIS}

\author{
SATISH KUMAR ${ }^{1}$, ARUN KUMAR GUPTA ${ }^{2}$ \& PANKAJ CHANDNA ${ }^{3}$ \\ ${ }^{1}$ Research Scholar, Department of Mechanical Engineering, National Institute of Technology, Kurukshetra, Haryana, India \\ ${ }^{2}$ Associate Professor, Department of Mechanical Engineering, M. M. E. C., Maharishi \\ Markandeshwar University, Mullana Ambala, Haryana, India \\ ${ }^{3}$ Professor, Department of Mechanical Engineering, National Institute of Technology Kurukshetra, Haryana, India
}

\begin{abstract}
The increased speed and weight of modern Bus puts the components of a Bus body in a highly dynamic load situation. Bus body is the core component in a vehicle. A classic finite element model of the Bus body is established that focuses on analyzing the behavior of a bus body during static and dynamic load conditions. A finite element model of a pre-stressed bus body is established for static load conditions. The purpose of this research work is to analyze the structural response of the bus body for static, dynamic, and impact loading conditions. In order to conduct this analysis, Finite element Method is applied and ANSYS (FEM Tool) is used. The finite element model is constructed from the structural data and drawings provided by DELHI TRANSPORT CORPORATION (DTC). The research work determines the structural response under the above said loading by evaluating the maximum deflection and stress pattern. The results are presented in the form of graphs and data along with the three-dimensional model of the bus body.

KEYWORDS: Static Load, Dynamic Load, Bus Body Structure, Pre-Stressed \& Finite Element Model
\end{abstract}

Received: Dec 02, 2017; Accepted: Dec 22, 2017; Published: Jan 19, 2018; Paper Id.: IJMPERDFEB201880

\section{INTRODUCTION}

One of the technical innovations of the modern world and of course always allowing room for progress, buses have taken the centre stage in transporting people through long distances with maximum safety, comfort, minimum cost, reduced timing, and through proper adherence of standard rules. For many years, buses have been widely used in India as a successful mean for public transportation within the city as well as from city to city. The buses form the major component of surface transportation in India as buses connect most of the villages. When these buses had been used first, since then not much attention has been paid for the improvement of the body of the buses. These bus body designs have, however, been giving reasonable service, although their efficiency had hardly been evaluated or tested scientifically. In the absence of such evaluation tests, the vehicle designs cannot be termed as optimal designs from operational and maintenance costs point of view as also from structural performance; passenger comfort and other operational requirement point of view. Everyone tried to improve mechanical components such as engine, transmission systems, clutches, gear box, etc. But, bus body structure could not win the hearts of designers. Now, designers are also becoming serious for the design of bus bodies. The damages and human injuries during accidents had been sufficient to draw the attention of designers towards it.

Considering the above deficiencies, scientific evaluation of some of the existing bus body designs is 
needed, using techniques such as Finite Element Method (FEM). This will help to access their conformance to various performance standards besides structural sturdiness and to identify the shortcomings therein. Suitable modifications in design, if required, need also be brought out in this process.

The widespread availability of computing power to designers and engineers has created a renewed interest in predictive techniques in automotive design analysis. With the availability of powerful computer aided analysis tool like ANSYS, it is nowadays possible to optimize the structural parameters without scarifying the strength and stiffness of vehicle. Using this computer software, any structure can be analyzed for further design and improvement. One such attempt has been done in this research work, by doing structural analysis of existing bus body to access their performance under static, dynamic, and impact loading conditions.

\subsection{Objective}

The objectives of this study are:

- Modeling the bus body framework in ANSYS.

- Static Analysis of Bus Body without considering the chassis and leaf spring.

- Static Analysis of Bus Body considering the chassis frame and leaf spring.

- 4) Dynamic Analysis of Bus Body.

- 5) Impact Analysis of Bus Body.

\section{BUS BODY STRUCTURE}

The bus body used for the study has a narrow body with a gross weight of $3055 \mathrm{~kg}$ (seated) and $1080 \mathrm{~kg}$ (standee). The bus body used for the study has a narrow body of overall dimension (10769x2530x3000) $\mathrm{m}$. It consists of two types of cross bearer sections - bus body of ISMC 100x50x5 mm Channel section as shown in Figure 1. There are some additional members like Body Side Pillar, Stump Pillar, Vent Rail, Cant Rail, Waist Rail, Seat Rail, Arch Sections, Diagonal Bracing, Roof sticks and Roof Longitudes, Floor Longitudes, Sole Bar of material CRCA M. S and cross members to strengthen the joints.

\subsection{Specification of Bus Body Structure}

The bus body under consideration for the analysis for the analysis is built on the Ashok Leyland Chassis having specifications as given below:

AL-Viking $5639 \mathrm{~mm}$ WB chassis with 60\% ROH.

The major dimensions of the bus body according specifications provided by DELHI TRANSPORT CORPORATION (DTC) to the manufacturers are given as under:

- Overall length

- Overall width

- Overall height

- Saloon height
$10769 \mathrm{~mm}$

$2530 \mathrm{~mm}$

$3000 \mathrm{~mm}$

$1934 \mathrm{~mm}$ 
- Pillar to Pillar Distance

- $\quad$ Seat back to back

- No. of seats (excluding driver)
$1450 \mathrm{~mm}$

$700 / 695$

49

Table 1: Properties of Mild Steel

\begin{tabular}{|l|c|l|c|}
\hline Young's Modulus(N/Mm2) & Density & Poisson's Ratio & Shear Modulus \\
\hline EX 21,0000 & DENS 7.87e-006 & PRXY 0.3 & GXY 8000 \\
\hline
\end{tabular}

Chassis Frame is of mild steel and is not as such a part of Bus body, but the part of chassis on which body is mounted. For the above purpose, the bus body specification data and drawings have been taken from DELHI TRANSPORT CORPORATION (DTC). These drawings and data are first analyzed thoroughly and then the bus body structure is digitized to create a finite element model in ANSYS. The model is then analyzed for the static loading conditions and the performance of the structure is studied. To access the performance of the bus body in respect of structural sturdiness, safety of occupants, comfort level, etc., dynamic and free vibration analysis has been undertaken for various time dependent loading conditions. To check the structure against crash worthiness impact analysis has also been done. The final results of the study would aim at facilitating evaluation of the existing bus body design.

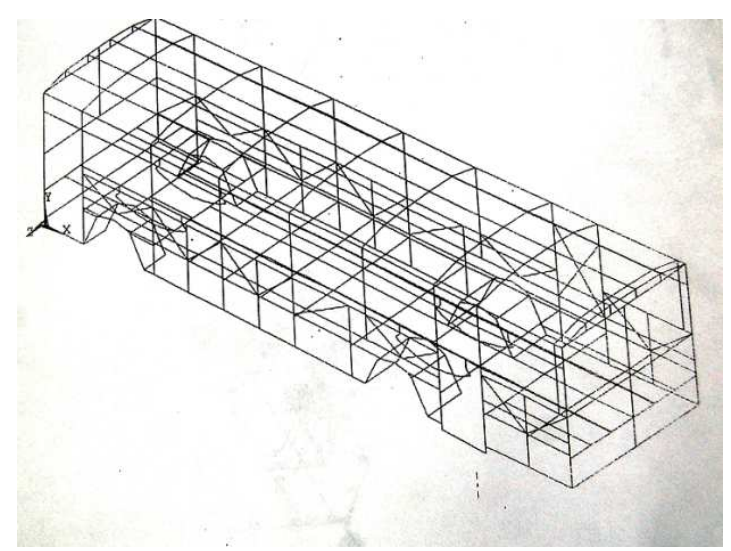

Figure 1: Model of Bus Body

The following table gives the various geometric parameters of the numbers used in the bus body, which are used as real constants in the ANSYS for Beam Element. The notations used are according to the ANSYS as explained in the modeling procedure.

Table 2: Various Geometric Parameters of the Members Used in the Bus Body

\begin{tabular}{|c|l|c|c|c|c|}
\hline Sr. No. & \multicolumn{1}{|c|}{ Member name } & $\begin{array}{c}\text { Area }\left(\mathbf{m m}^{\mathbf{2}}\right) \\
\left(\mathbf{m m}^{\mathbf{2}}\right)\end{array}$ & $\begin{array}{c}\mathbf{I}_{\mathbf{Z Z}} \\
\left(\mathbf{m m}^{\mathbf{4}}\right)\end{array}$ & $\begin{array}{c}\mathbf{I}_{\mathbf{Y Y}} \\
\left(\mathbf{m m}^{\mathbf{4}}\right)\end{array}$ & Mass/unit length $\mathbf{( K g / m )}$ \\
\hline 1 & Cross bearer Channel section & 950 & 196880 & 143291 & 7.5 \\
\hline 2 & Body Side pillar & 475 & 234739 & 123489 & 3.7 \\
\hline 3 & Stump pillar & 384 & 193152 & 102272 & 3.0 \\
\hline 4 & Vent Rail & 304 & 73365 & 73365 & 2.4 \\
\hline 5 & Cant Rail & 384 & 193152 & 102272 & 3.0 \\
\hline 6 & Waist Rail & 384 & 193152 & 102272 & 3.0 \\
\hline 7 & Seat Rail & 351 & 43302 & 128083 & 2.8 \\
\hline 8 & Sole Bar & 231 & 35818 & 35818 & 1.8 \\
\hline 9 & Diagonal bracing & 304 & 73365 & 73365 & 2.4 \\
\hline
\end{tabular}




\begin{tabular}{|c|l|c|c|c|c|}
\hline \multicolumn{7}{|c|}{ Table 2: Contd., } \\
\hline 10 & Roof Sticks and roof longitudes & 312 & 140256 & 76181 & 2.5 \\
\hline 11 & Floor Longitudes & 403 & 286655 & 11514 & 3.2 \\
\hline 12 & Wheel arch section & 231 & 35818 & 35818 & 1.8 \\
\hline 13 & Chassis frame & 2338 & 1029500 & 17320240 & 18.4 \\
\hline
\end{tabular}

\section{MATHEMATICAL FORMULATION}

The bus body structure has been idealized as a 3-D Frame. To formulate the displacement method of analysis the members of the framed structure has been treated as three-dimensional beam elements having six degrees of freedom at each node. The real constants i.e. geometric properties of the beam elements have been calculated by using data provided in section-2. ANSYS recognize this beam element as BEAM4 in its element library. BEAM4 is a uniaxial beam element with tension, compression, bending, and torsion capabilities. The element has six degree of freedom at each node: translations in nodal $\mathrm{x}, \mathrm{y}, \mathrm{z}$ directions and rotations about the nodal $\mathrm{x}, \mathrm{y}, \mathrm{z}$ axes. Stress stiffening and large deformation capabilities are also included.

\subsection{Discretization of Bus Body in to Finite Elements}

First step in the analysis of bus body structure is the modeling of it in the ANSYS. Bus body structure is discretized into elements having desired geometrical properties of the members as they are connected in Bus Body.

All the drawings of the bus body have been studied and coordinates of the different joints have been calculated. These joints, then assumed to be a nodal point between which elements are connected. This nodal data is then fed into ANSYS program and the whole model of the bus body is formulated by fitting beam elements having desired properties at their appropriate positions. As we have directly idealized bus body to be framework of elements, no need to go for meshing. Thus, model is ready for further analysis use.

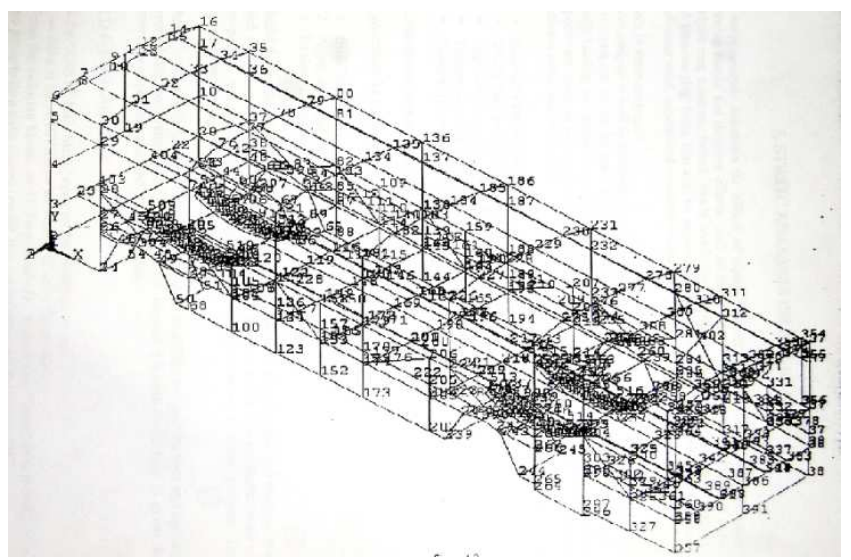

Figure 2: Discritization of Bus Body

As the whole analysis cannot be done in one step alone we have followed stepwise approach towards the static analysis of buys body structure with simplified loading and constraint equation then making it more realistic in further stages to obtain the desired results. Some modeling amendments have also been done to make it realistic analysis. Following different cases have been considered while doing analysis:

- Bus body without chassis frame and leaf spring: 
- Bus body with uniform cross-section of 60x40x12 SWG tubular applied to all members of the bus body (this is to get a feel of the analysis).

- Bus body with those cross-sections, being currently used in DTC buses.

- Bus body along with chassis frame and leaf spring and as per DTC construction. The chassis frame and leaf spring specifications are according to 'Chassis Specification Sheet' provided by Messrs Ashok Leyland Ltd, Chennai

The overall geometry of the Bus Body is modeled in ANSYS by defining the Nodes in the global Cartesian coordinate system, which specify various principal coordinates to define the body. These nodes simulate the joints in the body where various members are connected.

\section{RESULT AND ANALYSIS OF BUS BODY STRUCTURE}

Modeling the bus body framework in ANSYS; applying given boundary conditions and externally and internally applied loads by following the steps discussed in the previous sections, a finite element solution of the structure is run for static analysis. After doing the static analysis, we arrived at the results which are discussed in detail in the following sections. The results have been categorized according to two cases discussed in previous sections.

\subsection{Static Analysis of Bus Body}

A static analysis calculates the effects of steady loading conditions on a structure while ignoring inertia and damping effects, such as those causes by time-varying loads. The procedure for static analysis consists of three basic steps:

- $\quad$ Build the model

- Apply loads and obtain the solution

- Review the results

Build the Model: To build the model, we have to specify the job name and analysis title and then use pre-processor to define the element types, element real constants, material properties, and the model geometry. These tasks are common to most analysis. The previous section explains them in detail.

Apply Loads and Obtain the Solution: In this step, we define the analysis type and options, apply loads, constraints, and begin the finite element solution.

Review the Results: Results from the static analysis consists of the following data:

- Primary Data

- $\quad$ Nodal displacements (UX, UY, UZ, ROTX, ROTY, ROTZ)

- Derived data

- Nodal and element stresses

- Nodal and element strains

- Element forces

- Nodal reaction forces 
We can review these results using third component of ANSYS i.e. post processing.

Deformed Shape: The deformation pattern of the Bus Body because of above loading condition is as shown in Figure 3 which also shows the location of maximum and minimum deflection in Y-direction.
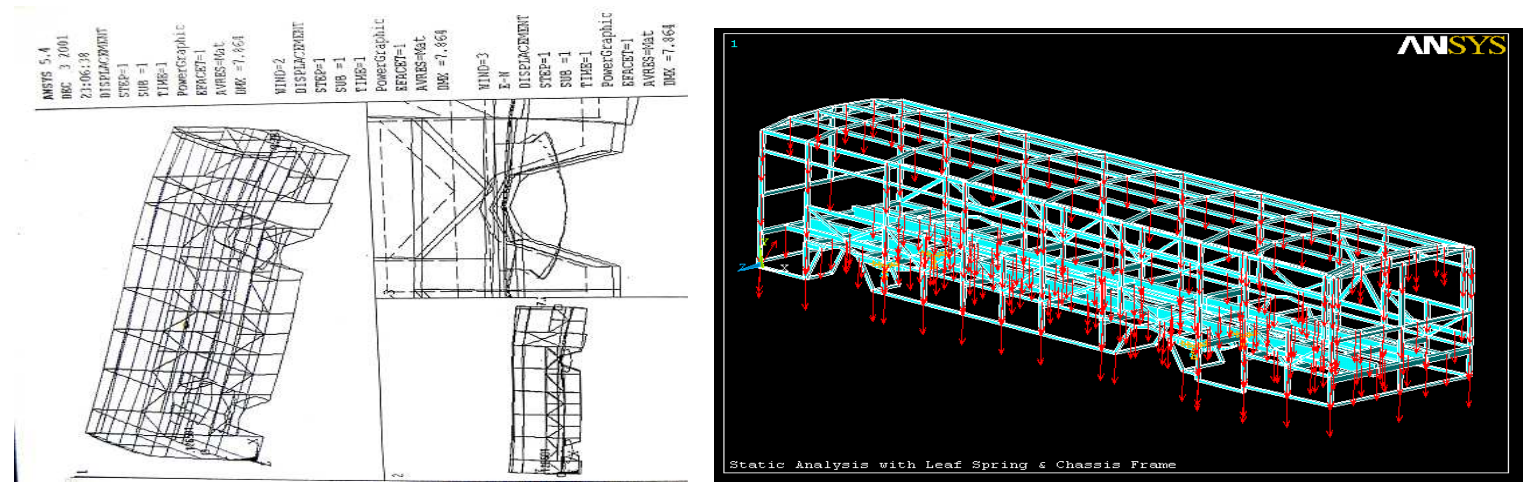

Figure 3: Static Analysis with Leaf Spring \& Chassis Frame

Displacements: The maximum values of deflections for all degrees of freedom are given below:

Table 3: Maximum Values of Deflections for All Degrees of Freedom

\begin{tabular}{|l|c|c|c|c|c|c|}
\hline \multicolumn{1}{|c|}{ Degree of } & UX & UY & UZ & ROTX & ROTY & ROTZ \\
\hline Node no. & 391 & 228 & 264 & 338 & 337 & 385 \\
\hline Value & -0.82 & -5.77 & -2.81 & -0.005 & 0.001 & 0.004 \\
\hline
\end{tabular}
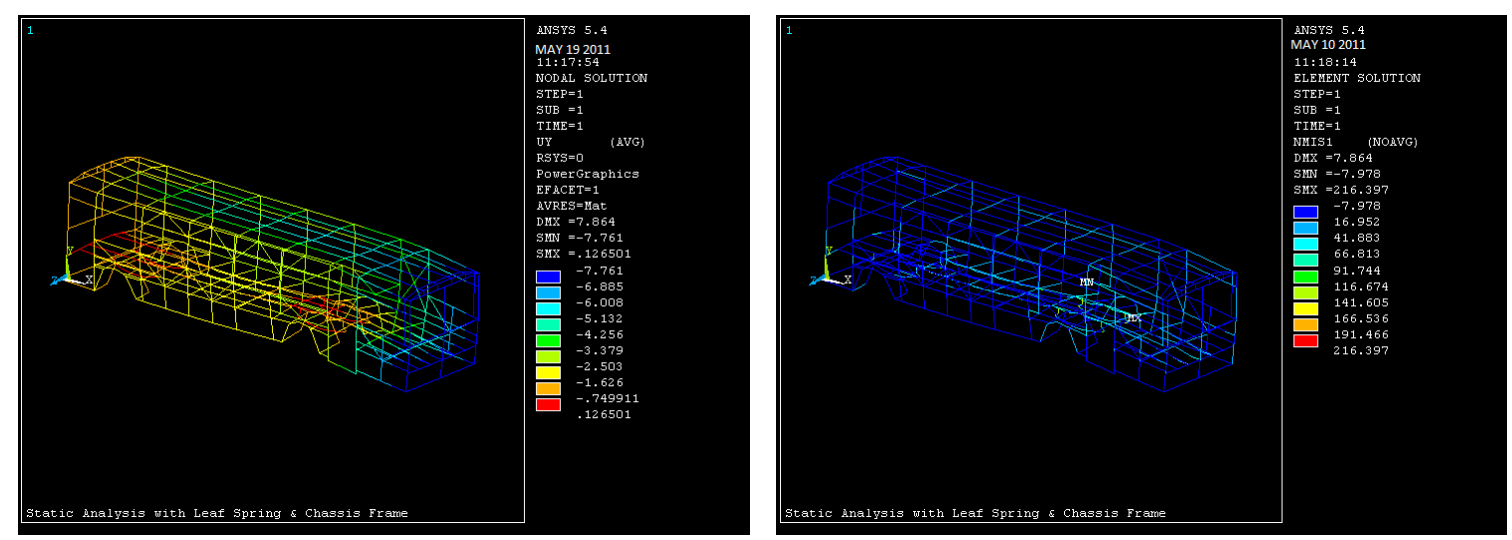

Figure 4: Static Analysis with Leaf Spring \& Chassis Frame

\subsection{Dynamic Analysis of Bus Body}

The Bus Body structure was analyzed for static loading conditions in the previous section. The results we got are for steady state conditions. The buses in their normal operating conditions are subjected to various types of time dependent loading (dynamic) conditions (such as acceleration, braking and speed breaker etc.). To study the response of the bus body under these loading conditions we are going for Dynamic Analysis.

The graphs of the displacements versus time in $\mathrm{X}, \mathrm{Y}$, and $\mathrm{Z}$ direction for the nodes at which the maximum deflection occurs are shown in Figure 5. (a) and (b). The graphs of total maximum and minimum stresses versus time are also given in the Figure 5

From the graphs we observe that the deflections are following the load time diagram. The Y-deflection reaches a 
maximum value of $9.0 \mathrm{~mm}$ (in downward direction) in 10 seconds and then the Bus Body settles down to final Ydeflection value of $8.2 \mathrm{~mm}$. After 10 seconds we can see that the response is stabilizing and its is undamped and sinusoidal in nature since damping is ignored during the analysis. From these sinusoidal response the frequency is coming to be 0.2 $\mathrm{Hz}$. Thus we are able to get the first natural mode. Same observations can be made for $\mathrm{X}$ and $\mathrm{Z}$ - displacements which are revealed from the respective graphs.

The maximum and minimum stresses are also behaving in the similar fashion. The stress values are coming higher in the rear leaf spring region. In the body of the Bus the stresses are not coming so high and values are just similar to static analysis case.
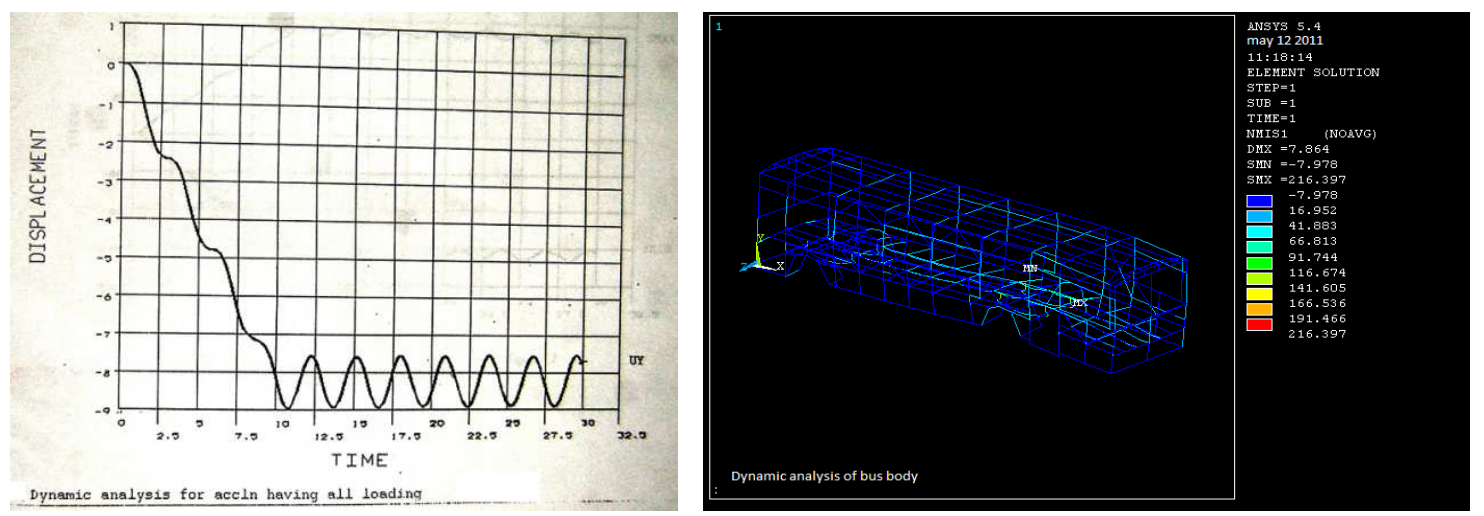

Figure 5: Dynamic Analysis of Bus Body Having All Loading

The graphs of the displacements versus time in $\mathrm{X}, \mathrm{Y}$, and $\mathrm{Z}$ direction for the nodes at which the maximum deflection occurs are shown in Figure 6. The graphs of total, maximum and minimum stresses versus time are also given in the Figure 6.

From the graphs we observe that the deflections are following the load time diagram. The Y-deflection reaches a maximum value of $9.0 \mathrm{~mm}$ (in downward direction) in 10 seconds and then the Bus Body settles down to final Ydeflection value of $8.2 \mathrm{~mm}$. After 10 seconds we can see that the response is stabilizing and its is undamped and sinusoidal in nature since damping is ignored during the analysis. From these sinusoidal response the frequency is coming to be 0.2 Hz. Thus we are able to get the first natural mode. Same observations can be made for $\mathrm{X}$ and $\mathrm{Z}-$ displacements which are revealed from the respective graphs.

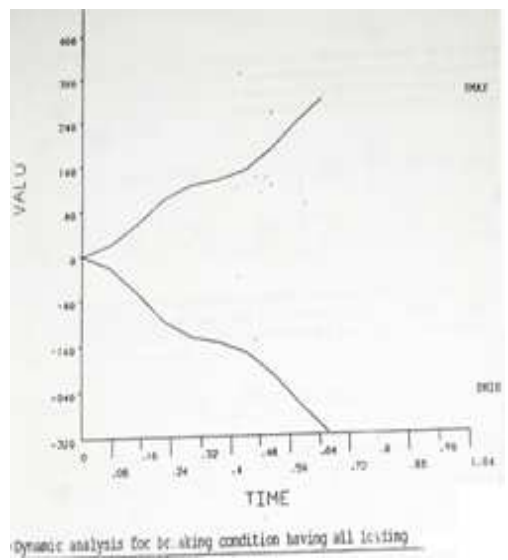

Figure 6: Dynamic Analysis for Breaking Condition Having All Loading 


\subsection{Impact Loading of Bus Body}

When a large force is suddenly applied to an elastic body (as by a blow) then it is called as impact loading condition. In this case a relatively large moving mass strikes a structure and the kinetic energy of the moving mass is assumed to be converted into strain energy in the structure. All portions of the structure and moving mass are assumed to stop moving simultaneously. A wave of stress is propagated through a body during impact. A special case of this loading generally called sudden loading, which we have considered for analysis purpose. For this analysis, we consider a body of mass 15 tons travelling at a speed of $54 \mathrm{~km} \ldots \ldots . \mathrm{m} / \mathrm{sec}$ ) is impacting on the DTC Bus body, which is assumed to be stationary. To siumlate actual impact we assumed that momentum of the moving mass comes to zero in 0.14 sec thereby producing a maximum force of $2250 \mathrm{KN}$. This force is distributed equally on the front end nodes of the Bus body and applied in $0.14 \mathrm{sec}$.
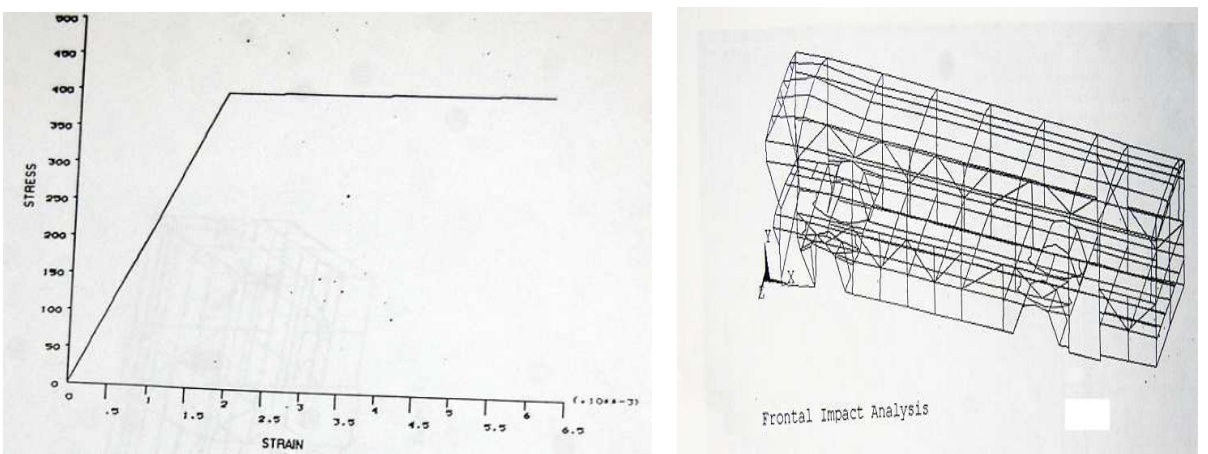

Figure 7: Stress Strain Diagram and Frontal Impact Analysis

The deformed shape $f$ the Bus body after impact is given in the Figure 7. The maximum deflection is coming in the X-direction $(218 \mathrm{~mm})$, which is coming at the front end node. The maximum deformation in Y-direction is coming on the front near side wheel arch while the Z- direction maximum deformation is coming on the corner node of the front door. Thus maximum collapse occurs for cabin portion of the Bus body.

The Strain Energy distribution for the bus body is shown in Figure. The energy absorbed at the point of application of load is $7.4 \mathrm{KN}-\mathrm{m}$.

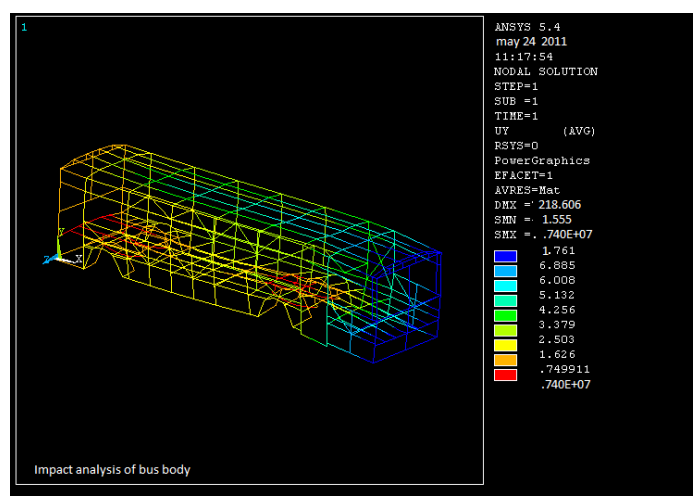

Figure 8: Impact Analysis of Bus Body

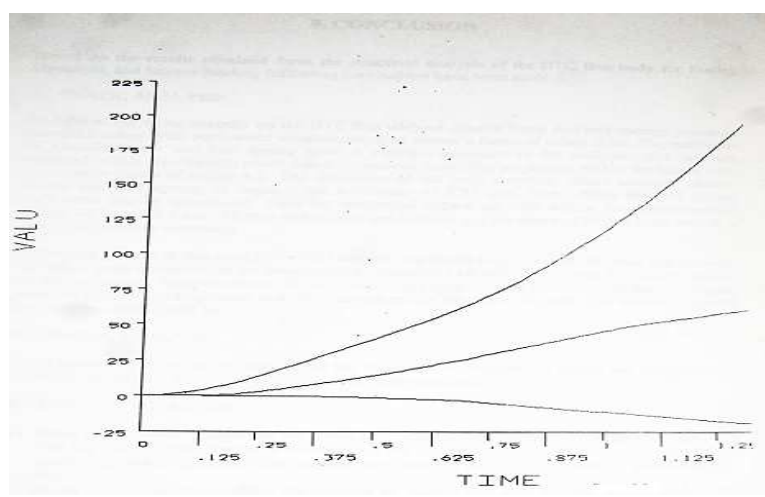

Figure 9: Deflection Versus Time Graph

The graphs of deflection-versus-time for maximum $\mathrm{X}$ and Y-deflection are given in the Figure 9

Following table gives the maximum deflection for all degrees of freedom. 
Table 4: Maximum Deflection for All Degrees of Freedom Under Impact

\begin{tabular}{|l|c|c|c|c|c|c|}
\hline \multicolumn{1}{|c|}{ Degree of } & UX & UY & UZ & ROTX & ROTY & ROTZ \\
\hline Node no. & 19 & 47 & 24 & 31 & 3 & 13 \\
\hline Value & 218.23 & 64.10 & -20.79 & 0.072 & 0.327 & 0.311 \\
\hline
\end{tabular}

\section{CONCLUSIONS AND FUTURE SCOPE}

Results of the static analysis on the DTC Bus without chassis frame and leaf springs involves normal loading with equivalent acceleration load show a factor of safety 3.56. The deflection of the body structure, which includes chassis frame and leaf spring, is coming out maximum of $8.25 \mathrm{~mm}$, from which the recommended values of 10 to $12.5 \mathrm{~mm}$. Higher deflections are occurring at the rear end of bus body which is due to high rear overhang. The stress pattern in the remaining body structure is such that cross bearers and floor longitudes are highly stressed (next to leaf springs) and other members are very low stressed. The stresses in body are ranging from 10-90 MPa. From modal analysis we are able to get the fundamental frequencies which coming to be 0.19955. All natural modes of vibration have been extracted. From the dynamic analysis of DTC bus body considering acceleration effect we conclude that for the considered case in our analysis the results are very near to that coming in the equivalent static analysis. Thus we can consider the acceleration loads in static analysis itself. In the case sudden braking the stresses are higher, but still they are within limits. The body members such as cross bearers and floor longitudes are also stresses but with a low value reaching to $80 \mathrm{MPa}$. Rest all members are very low stressed. Impact analysis has been undertaken to get a feel of structural response of bus body for a heavy sudden load (applied at the front side). The maximum strain energy absorbed by the body is coming out to $7.4 \mathrm{KN}-\mathrm{m}$. Also the stress pattern shows the propagation of stress wave through the body.

From the analysis undertaken for static and dynamic loading condition, we see that even in the worst conditions the maximum stress obtained in the members of the DTC Bus body is of the order of $30 \mathrm{MPa}$. This is very less compared with the stress induced in the cross bearers and floor longitudes (80 MPa).

The above results help us to conclude that the present DTC Bus is safe to a certain extent. The structural performance can be improved by providing proper reinforcement to the highly stressed members (cross bearers and floor longitude) and replacing low stressed members (roof longitudes and sticks, waist rail, vent rail, etc) by sections having reduced sectional properties.

\section{REFERENCES}

1. Zhu and Chai (1989), "Finite Element Analysis of Structure of Dumping Truck Based on ANSYS" International Journal of Mech Engg Number; 28:1875-89.

2. Zhigang and Maotao (2002), "Development of Model Simplifications of Bus Body Connections." Automobile college," conference-paper, int-ansys-conf-24, Jiangsu University, China

3. Lan, Chen and Lin (2004), “Comparative analysis for bus side structures and lightweight optimization." Proceedings Institution of Mechanical Engineers, Journal Automobile Engineering Vol. 218 issue 10, page 1067-1075.

4. Manokruang and Butdee (2009), "Methodology of Bus-Body Structural Redesign for Lightweight Productivity Improvement." AIJSTPME 2(2): 79-87

5. Butdee, S and Vignat, F (2008), "TRIZ method for light weight bus body structure design.” Journal of Achievements in Materials and Manufacturing Engineering.”, volume 31,issue 2, pp- 456-462. 
6. Kim, H. S, Hwang, Y. S, and Yoon, H. S.,(2002) “Dynamic Stress Analysis of a Bus system.” ASME Journal of Applied Mechenics, publication on scribd, vol 12, pp 69-A77.

7. Hwai, Bin Mu and Kraig Warnemuende, (2003) "Failure analysis of FRP sandwich bus panels by finite element method" Department of Civil and Environmental Engineering, composite part B-34, pp 51-58.

8. Wu, Mu and Warnemuende K, (2001) “ Fiberglass reinforced plastic composite bus body structural integrity analysis.” Final report to the Michigan Department of Transportation, the Urban and Public Transportation Passenger Transportation Division and the Michigan Transit Center for Excellence.

9. Ashwani Sharma \& M. A. Murtaza, Modeling and Finite Element Analysis of Vertical Axis Wind Turbine Rotor Configurations, International Journal of Mechanical and Production Engineering Research and Development (IJMPERD), Volume 6, Issue 3, May - June 2016, pp. 23-34

10. Lekhnitskii SG, (1963) “Theory of elasticity of an anisotropic elastic body.” San Francisco: Holden-Day.

11. Librescu and Hause, (2000) "Recent developments in the modeling and behavior of advanced sandwich constructions: a survey." Compos Struct;48:1-17.

12. Mallikarjuna, Kant T(1993). "A critical review and some results of recently developed refined theories of fiber-reinforced laminated composites and sandwiches." Compos Struct;23:293-312.

13. Mallikarjuna, Kant T. (1989) "Free vibration of symmetrically laminated plates using a high order theory with finite element technique.” Int J Numer Mech Engng;28:1875-89.

14. Correia and Soares, (1997) "Design sensitivity analysis and optimal design of composite structures using higher order discrete models.” Engng Optim;29:85-111.

15. Pawan S. Amrutkar et al., Design Validation of Radiator through Finite Element Analysis and Heat Rejection Validation through Experimental Test, International Journal of Automobile Engineering Research and Development (IJAERD), Volume 5, Issue 4, November - December 2015, pp. 1-10

16. Botello S, Oñate E, Canet JM. (1999) “ A layer-wise triangle for analysis of laminated composite plates and shell.” Comput Struct;70: 635-46.

17. Reddy JN. (1997) "Mechanics of laminated composite plates”-theory and analysis. Boca Raton: CRS Press;.

18. Reddy JN. (1987) “A generalization of two-dimensional theories of laminated composite plate." Commun Appl Numer Meth;3: 173-80.

19. Zhou Yang, Wang Kui, Xiong Yumin and Zhang Buhan, (2012) "Study of Power System Online Dynamic Equivalent Based on Wide Area Measurement System" Energy Procedia 161768 - 1775.

20. H. Burak Ustaoğlu, Sena Ayhün and Gökay Simitçioğlu. (2015) "Static and Dynamic Analysis of Plastic Fuel Tanks Used in Buses.” Procedia Engineering 101509 - 517.

21. Dr. R. Rajappan, M. Vivekanandhan. "Static and Modal Analysis of Chassis by Using Fea." The International Journal Of Engineering And Science, Volume 2, Issue 2 (2013), Pages, 63-73.

22. Davalsab. M. L, Prof Anand. S. N, Sachin Prabha,. "Explicit dynamic analysis of automotive bus body Structure during catastrophic frontal crash with Expulsion system" International Journal of Advances in Scientific Research and Engineering,ISSN: 2454-8006,Vol. 03, Issue 5, June -2017.

23. D. Kishore Kumar, K. Sambasivarao, (2014) "Static and Dynamic Analysis of Railway Track Sleeper" International Journal 
of Engineering Research and General Science Volume 2, Issue 6, ISSN 2091-2730. 
